\title{
Thrombospondin-1/CD47 signaling modulates transmembrane cation conductance, survival, and deformability of human red blood cells
}

Rosi Bissinger ${ }^{1}$, Polina Petkova-Kirova ${ }^{2}$, Olga Mykhailova ${ }^{3,4}$, Per-Arne Oldenborg ${ }^{5}$, Elena Novikova ${ }^{5}$, David A. Donkor ${ }^{6,7}$, Thomas Dietz ${ }^{8}$, Abdulla Al Mamun Bhuyan ${ }^{9}$, William P. Sheffield ${ }^{6,7}$, Marijke Grau ${ }^{8}$, Ferruh Artunc ${ }^{1,10,11}$, Lars Kaestner ${ }^{12,13}$, Jason P. Acker ${ }^{3,4}$ and Syed M. Qadri ${ }^{6,714^{*}}$ (i)

\begin{abstract}
Background: Thrombospondin-1 (TSP-1), a Ca ${ }^{2+}$-binding trimeric glycoprotein secreted by multiple cell types, has been implicated in the pathophysiology of several clinical conditions. Signaling involving TSP-1, through its cognate receptor CD47, orchestrates a wide array of cellular functions including cytoskeletal organization, migration, cell-cell interaction, cell proliferation, autophagy, and apoptosis. In the present study, we investigated the impact of TSP-1/ CD47 signaling on $\mathrm{Ca}^{2+}$ dynamics, survival, and deformability of human red blood cells (RBCs).

Methods: Whole-cell patch-clamp was employed to examine transmembrane cation conductance. RBC intracellular $\mathrm{Ca}^{2+}$ levels and multiple indices of RBC cell death were determined using cytofluorometry analysis. RBC morphology and microvesiculation were examined using imaging flow cytometry. RBC deformability was measured using laser-assisted optical rotational cell analyzer.

Results: Exposure of RBCs to recombinant human TSP-1 significantly increased RBC intracellular $\mathrm{Ca}^{2+}$ levels. As judged by electrophysiology experiments, TSP-1 treatment elicited an amiloride-sensitive inward current alluding to a possible $\mathrm{Ca}^{2+}$ influx via non-selective cation channels. Exogenous TSP-1 promoted microparticle shedding as well as enhancing $\mathrm{Ca}^{2+}$ - and nitric oxide-mediated RBC cell death. Monoclonal (mouse lgG1) antibody-mediated CD47 ligation using 1F7 recapitulated the cell death-inducing effects of TSP-1. Furthermore, TSP-1 treatment altered RBC cell shape and stiffness (maximum elongation index).
\end{abstract}

Conclusions: Taken together, our data unravel a new role for TSP-1/CD47 signaling in mediating $\mathrm{Ca}^{2+}$ influx into $\mathrm{RBC}$, a mechanism potentially contributing to their dysfunction in a variety of systemic diseases.

Keywords: Thrombospondin-1, CD47, Red blood cells, Calcium, Cation channels, Deformability

\footnotetext{
* Correspondence: syedm.qadri@ontariotechu.ca

${ }^{14}$ Faculty of Health Sciences, Ontario Tech University, Oshawa, ON, Canada

Full list of author information is available at the end of the article
}

(C) The Author(s). 2020 Open Access This article is licensed under a Creative Commons Attribution 4.0 International License, which permits use, sharing, adaptation, distribution and reproduction in any medium or format, as long as you give appropriate credit to the original author(s) and the source, provide a link to the Creative Commons licence, and indicate if changes were made. The images or other third party material in this article are included in the article's Creative Commons licence, unless indicated otherwise in a credit line to the material. If material is not included in the article's Creative Commons licence and your intended use is not permitted by statutory regulation or exceeds the permitted use, you will need to obtain permission directly from the copyright holder. To view a copy of this licence, visit http://creativecommons.org/licenses/by/4.0/ The Creative Commons Public Domain Dedication waiver (http://creativecommons.org/publicdomain/zero/1.0/) applies to the data made available in this article, unless otherwise stated in a credit line to the data. 


\section{Background}

Thrombospondin-1 (TSP-1), a multimodular $\mathrm{Ca}^{2+}$-binding trimeric matricellular glycoprotein, is secreted by a wide array of cells such as platelets, fibroblasts, macrophages, dendritic cells, vascular smooth muscle cells, keratinocytes, epithelial cells, endothelial cells, and several cancer cells [1-3]. Alterations in TSP-1 expression levels have been implicated in the pathophysiology of several clinical conditions including diabetes, cancer, renal failure, and cardiovascular diseases [4-6]. TSP-1 possesses interacting domains for a variety of proteins, which relay signals regulating a diverse range of cellular functions such as cytoskeletal organization, migration, cell-cell interaction, cell proliferation, autophagy, and apoptosis $[2,7,8]$. Mechanisms of TSP-1-induced apoptosis, widely characterized in endothelial and cancer cells, have been reported to involve caspases, NF- $k B$, Bax, Bcl-2, nitric oxide (NO), as well as p38 and c-Jun $\mathrm{N}$-terminal kinases $[9,10]$. TSP-1-induced apoptosis has been largely ascribed to its binding with tumor necrosis factor receptor-1, scavenger receptor $\mathrm{CD} 36$, and the integrin-associated protein CD47 [10]. CD47, a ubiquitously expressed glycosylated cell surface protein, regulates cell activation or survival, depending on the physiological context $[11,12]$. TSP-1 signaling via its cognate receptor CD47 has further been implicated in orchestrating cytoplasmic $\mathrm{Ca}^{2+}$ dynamics and, thus, influencing various physiological functions [12].

In mature red blood cells (RBCs), CD47 is associated with different membrane proteins forming linkages with both cytoskeletal and non-cytoskeletal cellular components [11]. CD47 is pivotal in inhibiting RBC phagocytosis via binding to signal regulatory protein $\alpha$ (SIRP $\alpha$ ) on macrophages, which counteracts phagocytosis of non-opsonized as well as IgG or complement-opsonized RBCs $[13,14]$. A decline of cell surface CD47 expression during $\mathrm{RBC}$ aging in vivo is believed to promote the clearance of senescent RBCs [15]. Furthermore, microparticle release during $\mathrm{RBC}$ storage has been reported to favor CD47 loss during storage of RBCs for transfusion [16]. Beyond its significance in RBC aging, CD47 mediates the interaction of fibrinogen with the $\mathrm{RBC}$ membrane [17], and may, therefore, contribute to RBC hyperaggregation and altered hemorheology in inflammatory conditions $[18,19]$.

Similar to apoptosis of nucleated cells [10], ligation of CD47 with monoclonal antibodies, TSP-1, or its derivative peptides has been shown to trigger phosphatidylserine (PS) exposure on RBC cell surface with a concomitant loss of their viability [20]. The mechanisms underlying this phenomenon in RBCs, however, remain elusive. PS externalization, a cardinal morphologic sign of cell death (sometimes also referred to as eryptosis), is stimulated by activation of $\mathrm{Ca}^{2+}$-sensitive scramblases
[21-23]. Influx of extracellular $\mathrm{Ca}^{2+}$ into the RBC cytoplasm is mediated by voltage-gated and voltageindependent non-selective cation channels (NSCC [24, 25]), which are activated by pathophysiologic cell stressors such as hyperthermia, oxidative stress, extracellular hyperosmolality, and starvation [21, 26]. Supraphysiologic $\mathrm{Ca}^{2+}$ overload in RBCs induces metabolic reprogramming [27], and activation of multiple enzymes [21], thereby eliciting cellular dysfunction and death. PSexposing RBCs are rapidly cleared from the circulation and catabolized by macrophages of the reticuloendothelial system in the spleen and liver [21,28].

In the present study, using cytofluorometric and electrophysiological approaches we examined the influence of CD47-dependent signaling, evoked by exogenous TSP-1 or antibody-mediated CD47 ligation, on $\mathrm{Ca}^{2+}$ dynamics in human RBCs. We further studied the effect of TSP-1 exposure on multiple parameters of RBC deformability and cell death.

\section{Methods \\ RBCs and reagents}

Leuko-depleted RBC concentrates were provided by Canadian Blood Services (CBS) Network Centre for Applied Development (netCAD, Vancouver, BC, Canada) after prior approval from the CBS Research Ethics Board (\#2015.022). For some experiments, these concentrates were provided by the blood bank of the University of Tübingen (\#184/2003 V), Germany, or by the blood bank of Norrlands University Hospital, Umeå, Sweden. Donor RBCs, drawn from refrigerated blood bags containing SAG-M additive solution, were washed twice in PBS (1000 $\times$ g for $10 \mathrm{~min})$ and subsequently incubated in vitro (1\% hematocrit unless indicated otherwise) at $37^{\circ} \mathrm{C}$ in Ringer's solution (pH 7.4) containing $125 \mathrm{mM}$ $\mathrm{NaCl}, 5 \mathrm{mM} \mathrm{KCl}, 1 \mathrm{mM} \mathrm{MgSO} 4,32 \mathrm{mM}$ HEPES, $5 \mathrm{mM}$ glucose, and $1 \mathrm{mM} \mathrm{CaCl}_{2}$. Sample sizes (number of RBC units; n) for control and treatment groups used in individual experiments are indicated in the figure legends. Where indicated, RBCs were incubated with recombinant human thrombospondin-1 (1-50 $\mu \mathrm{g} / \mathrm{mL}$; R\&D Systems, Minneapolis, MN, USA) or with anti-human CD47 mAb 1F7 (mouse IgG1), which was purified from hybridoma supernatants [29-31]. In some experiments, RBCs were treated with sodium nitroprusside (Sigma Aldrich, Taufkirchen, Germany) or amiloride (Sigma Aldrich), as described in the figure legends.

\section{Flow cytometry}

Multiple indices of RBC cell death were analyzed using flow cytometry. After incubation under the respective experimental conditions, RBCs were washed once and phospholipid scrambling, intracellular $\mathrm{Ca}^{2+}$, and the generation of reactive oxygen species were examined using 
annexin V-FITC (1: 200 dilution; ImmunoTools, Friesoythe, Germany), Fluo-3/AM ( $5 \mu \mathrm{M}$, Biotium, Hayward, USA), and 2',7'-dichlorodihydrofluorescein diacetate $(10 \mu \mathrm{M}$, Sigma) staining, respectively [32]. Ceramide abundance was determined using a previously described monoclonal antibody-based assay with a primary anticeramide antibody (1:50 dilution; clone MID15B4; Alexis, Grünberg, Germany) and a fluorescent secondary antibody (1:500 dilution; FITC-conjugated goat antimouse IgG/IgM; BD, San Jose, CA, USA) [32]. Data were analyzed using FlowJo software (FlowJo LLC, Ashland, OR, USA). Fluorescence parameters in all samples were analyzed at an excitation wavelength of $488 \mathrm{~nm}$ and an emission wavelength of $530 \mathrm{~nm}$.

RBC morphology and microparticle (MP) generation were examined simultaneously using high-throughput imaging flow cytometry, which enables qualitative phenotypic screening of both parent RBCs and MPs, and thereby circumvents the limitations of conventional flow cytometry [33]. Using differences in scattering intensities, RBCs, ghosts, and MPs were characterized and their concentrations (objects) were determined by extrapolating the area of each subpopulation for a given sample [33, 34]. To tackle inter-sample variability in $\mathrm{RBC}$ and MP counts in the control and treated groups, the relative concentration of MPs in the sample, calculated as a ratio of $\mathrm{RBC}$-derived $\left(\mathrm{CD} 47^{+} \mathrm{CD} 235 \mathrm{a}^{+}\right) \mathrm{MPs}$ to total $\mathrm{RBC}$, was determined. For $\mathrm{RBC}$ morphology index (MI) assessment, a sequentially-numbered set of individually captured RBC brightfield images (170 \pm 7 images per sample) was manually assigned by a human operator to six morphology subclasses: smooth discs (SDCs), crenated discs (CDCs), crenated discoids (CDDs), crenated spheroids (CSDs), crenated spheres (CSEs), smooth spheres (SSEs), and multiplied by fractional weights [35]:

$$
\begin{aligned}
\mathrm{MI}, \%=(\mathrm{SDCs} \times 1.0) & +(\mathrm{CDCs} \times 0.8)+(\mathrm{CDDs} \times 0.6) \\
& +(\mathrm{CSDs} \times 0.4)+(\mathrm{CSEs} \times 0.2) \\
& +(\mathrm{SSEs} \times 0) * 100) \\
& /(\mathrm{SDCs}+\mathrm{CDCs}+\mathrm{CDDs}+\mathrm{CSDs}+\mathrm{CSEs}+\mathrm{SSEs}) .
\end{aligned}
$$

After a 48 -h incubation with $50 \mu \mathrm{g} / \mathrm{mL}$ TSP-1 (at $40 \%$ hematocrit) in Ringer's solution, $75-\mu \mathrm{L}$ of the cell suspension was washed once and adjusted to $100 \mu \mathrm{L}$ with Ringer's solution. For qualitative analyses, the control and TSP-1-treated RBC samples containing all three subpopulations were then incubated at room temperature (30 min; under protection from light) with $5 \mu \mathrm{L}$ of CD47 PerCP$\mathrm{Cy}^{\mathrm{mm}} 5.5$ (BD Pharmingen ${ }^{\mathrm{m}}$, clone $\mathrm{B} 6 \mathrm{H} 12$ ) and $2.5 \mu \mathrm{L}$ of $20 \mu \mathrm{g} / \mathrm{mL}$ CD235a BV510 (BD Pharmingen ${ }^{\mathrm{Tm}}$, clone GAR2 (HIR2)). The samples were then examined on an ImageStreamX MkII instrument (ISX; Amnis/MilliporeSigma) equipped with 4 lasers $(405 \mathrm{~nm}, 488 \mathrm{~nm}, 642 \mathrm{~nm}, 785 \mathrm{~nm}$ (SSC)) and 3 objectives $(20 \times, 40 \times$, and $60 \times)$. All data was acquired at $60 \times$ magnification, $7 \mu \mathrm{m}$ core size and low flow rate. CD47 PerCP-Cy5.5 signals were collected in channel 5 (642-745 nm filter) and CD235a BV510 signals in channel 8 (505-570 nm filter). Channels 1 (420-480 $\mathrm{nm}$ filter) and 9 (570-595 $\mathrm{nm}$ filter) were used as Bright Field channels (BF1, BF2) and channel $12(745-800 \mathrm{~nm}$ filter) for SSC detection (Dark Field (DF) Scattering intensity). Data analyses was performed using Amnis IDEAS software (version 6.2).

\section{Electrophysiology}

Patch-clamp measurements were performed with a NPC-16 Patchliner (Nanion Technologies, Munich, Germany). The internal and external solutions were as follows: $\mathrm{KCl} 70 \mathrm{mM}$, KF $70 \mathrm{mM}, \mathrm{NaCl} 10 \mathrm{mM}$, HEPES $10 \mathrm{mM}$, MgATP $2 \mathrm{mM}$, EGTA $3 \mathrm{mM}$, and $\mathrm{CaCl}_{2} 1.2 \mathrm{mM}$ to give $120 \mathrm{nM}$ free $\left[\mathrm{Ca}^{2+}\right]_{\mathrm{i}}, \mathrm{pH}=7.2$ adjusted with $\mathrm{KOH}$ (internal) and $\mathrm{NaCl} 140 \mathrm{mM}, \mathrm{KCl} 4 \mathrm{mM}, \mathrm{MgCl}_{2} 5 \mathrm{mM}$, D-glucose $5 \mathrm{mM}$, HEPES $10 \mathrm{mM}, \mathrm{CaCl}_{2} 2 \mathrm{mM}, \mathrm{pH}=7.3$ adjusted with $\mathrm{NaOH}$ (external). In these solutions, the resistance of the chips was between 5 and $8 \mathrm{M} \Omega$. Gigaseal formation was facilitated using a seal enhancing solution as recommended by the Patchliner manufacturer and containing: $\mathrm{NaCl} 80 \mathrm{mM}, \mathrm{KCl} 3 \mathrm{mM}, \mathrm{MgCl}_{2} 10 \mathrm{mM}$, $\mathrm{CaCl}_{2} 35 \mathrm{mM}$, HEPES $10 \mathrm{mM}, \mathrm{pH}=7.3$ adjusted with $\mathrm{NaOH}$. Whole-cell configuration was achieved by negative pressure suction pulses between -45 mbar and 150 mbar and its formation judged by the appearance of sharp capacitive transients. Whole-cell patch-clamp recordings were conducted at room temperature using voltage steps from $-100 \mathrm{mV}$ to $80 \mathrm{mV}$ for $500 \mathrm{~ms}$ in 20 $\mathrm{mV}$ increments at $5 \mathrm{~s}$ intervals, the holding potential being set at $-30 \mathrm{mV}$. Whole-cell currents were assessed before (control) and after adding $50 \mu \mathrm{g} / \mathrm{mL}$ TSP-1. To reduce inter-cell variability, data are expressed as normalized current, which is the ratio of the current under specified experimental conditions, i.e. before and in the presence of $50 \mu \mathrm{g} / \mathrm{mL}$ at the membrane potentials used in the protocol, to the current at $+80 \mathrm{mV}$ determined $30-60 \mathrm{~s}$ before starting the control measurement.

\section{RBC deformability measurement}

RBCs were incubated ( $40 \%$ hematocrit) for $48 \mathrm{~h}$ at $37^{\circ} \mathrm{C}$. After incubation time, $250 \mu \mathrm{L}$ of control or TSP-1treated RBCs were washed once with Ringer's solution. Ten $\mu \mathrm{L}$ of the aliquot was transferred into $1 \mathrm{~mL}$ viscous PVP (polyvinylpyrrolidone; RR Mechatronics, The Netherlands) for RBC deformability measurements. RBC deformability was measured using the laser assisted optical rotational red cell analyzer (LORRCA; RR Mechatronics, The Netherlands). The two parameters used to describe $\mathrm{RBC}$ deformability are $\mathrm{EI}_{\max }$ and $\mathrm{K}_{\mathrm{EI}}$. The $\mathrm{EI}_{\max }$ is defined as the maximum elongation index predicted at an infinite shear stress. The $K_{E I}$ is the shear stress 
required to elongate to half the $\mathrm{EI}_{\max }$. These parameters are obtained using an Eadie-Hofstee linearization, which plots the measured EI values versus the $\mathrm{EI} /$ respective shear stress (EI/SS) [36]. The slope of the best fit line provides the $\mathrm{K}_{\mathrm{EI}}$ and the $\mathrm{y}$-intercept corresponds to the $\mathrm{EI}_{\max }$.

\section{Statistical analysis}

Data are expressed as arithmetic means \pm SEM. $n$ denotes the number of different donor RBCs studied. Statistical analysis was performed using ANOVA with Tukey's test as a post-test, $\mathrm{t}$ test or non-parametric Wilcoxon signed rank test by GraphPad Prism Version 8.4.3 (GraphPad Software, La Jolla, CA). A P-value less than 0.05 was considered statistically significant.

\section{Results}

\section{Effect of thrombospondin- 1 on $\mathrm{Ca}^{2+}$ homeostasis in} human red blood cells

The impact of TSP-1 treatment on RBC intracellular $\mathrm{Ca}^{2+}$ levels was examined using Fluo3 fluorescence in flow cytometry analysis. As shown in Fig. 1a and b, exposure of RBCs to TSP-1 $(50 \mu \mathrm{g} / \mathrm{mL})$ for $48 \mathrm{~h}$ significantly enhanced the percentage of RBCs with increased Fluo3 fluorescence indicating increased cytoplasmic $\mathrm{Ca}^{2+}$ concentration. Whole-cell patch-clamp experiments were performed to elucidate whether TSP-1 influences cation channel activity. As illustrated in Fig. 1c and d, exposure of RBCs to $50 \mu \mathrm{g} / \mathrm{mL}$ TSP-1 using physiological internal and external solutions induced an increase in an inward conductance, indicating a possible cation flux into the cells, that may be related to the increase in the intracellular $\mathrm{Ca}^{2+}$ concentration. Furthermore, treatment with $1 \mathrm{mM}$ amiloride, a cation channel inhibitor [28], abrogated the TSP-1-induced increase in the inward conductance (Fig. 1e). In addition, amiloride also blocked an outward current that was not induced by TSP-1.

\section{Effect of thrombospondin-1 on phosphatidylserine externalization, sphingomyelinase activation, and the generation of reactive oxygen species in human red blood cells}

Enhanced cytosolic $\mathrm{Ca}^{2+}$ content is expected to activate scramblases which, in turn, elicit cell membrane PS externalization. We observed that a 48-h incubation of

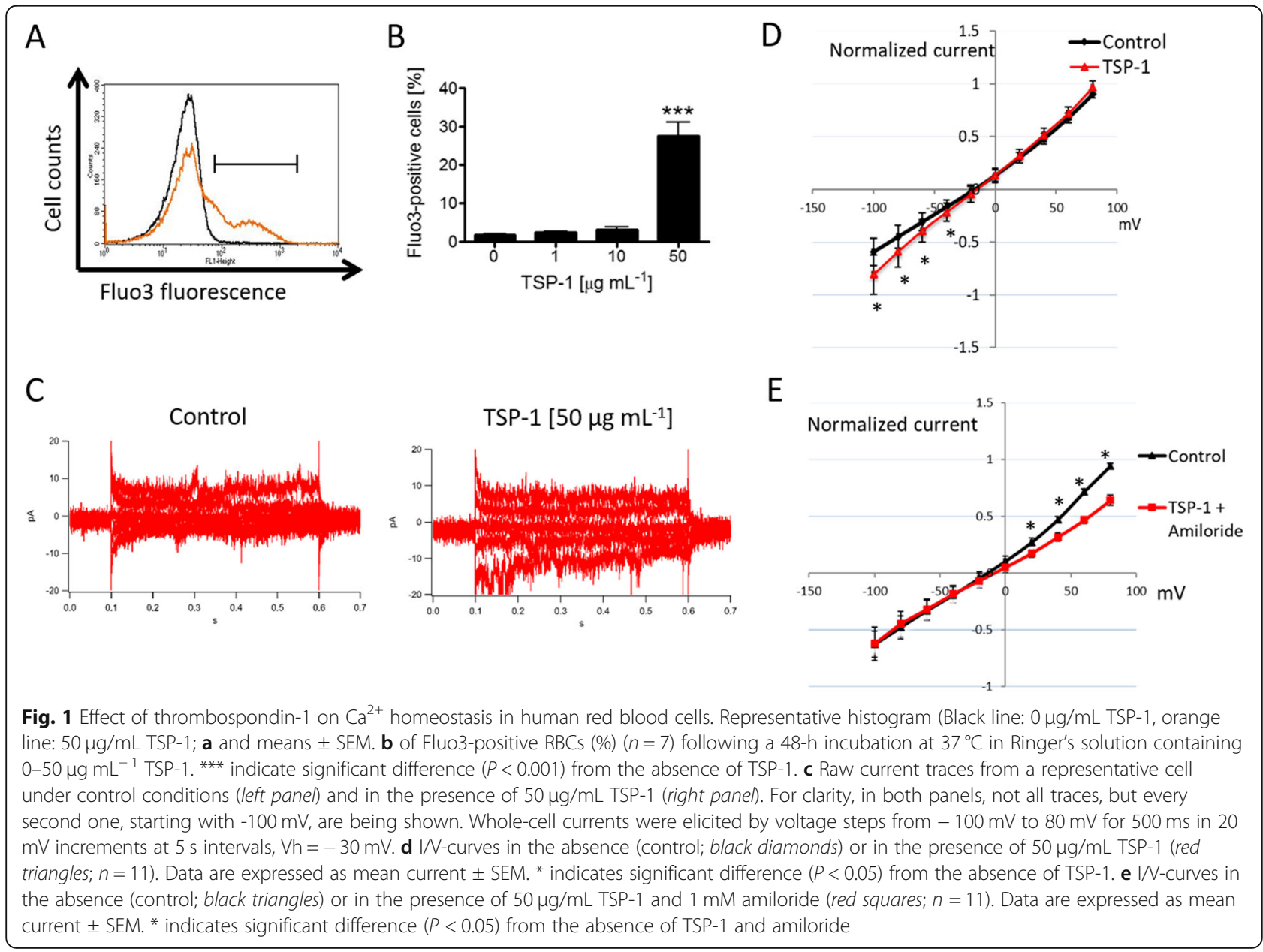


RBCs in the presence of TSP-1 $(50 \mu \mathrm{g} / \mathrm{mL})$ significantly increased the percentage of annexin V-positive RBCs, reflecting cell membrane PS exposure (Fig. 2a and b). We then interrogated the extent to which $\mathrm{Ca}^{2+}$ influx contributes to PS externalization triggered by TSP-1. Blocking $\mathrm{Ca}^{2+}$ entry via NSCC using amiloride $(1 \mathrm{mM}$ [26]; Fig. 2c) or removal of extracellular $\mathrm{Ca}^{2+}$ (Fig. 2d) significantly blunted, but did not abolish, TSP-1-induced PS exposure suggesting that increased $\mathrm{Ca}^{2+}$ entry participates in, but does not completely account for, TSP-1induced cell death. As TSP-1-induced PS exposure was not abolished by extracellular $\mathrm{Ca}^{2+}$ removal, we hypothesized that non- $\mathrm{Ca}^{2+}$-dependent mechanisms may contribute to the breakdown of phospholipid asymmetry. Multiple recent studies have shown the role of TSP-1 in modulating NO signaling in various cell types (reviewed in [3]). We, thus, explored whether NO-mediated signaling similarly modulates TSP-1-induced alterations in RBCs. As shown in Fig. 2e, treatment of RBCs with the NO donor sodium nitroprusside $(1 \mu \mathrm{M})$ significantly reduced TSP-1-induced PS externalization, suggesting the involvement of this mechanism in concert with $\mathrm{Ca}^{2+}$ dependent signaling leading to $\mathrm{RBC}$ cell death. We then examined whether TSP-1 elicits oxidative stress and sphingomyelinase activation, putative RBC cell death effectors [21]. As shown in Fig. 2f and g, a 48-h exposure of RBCs to $50 \mu \mathrm{g} / \mathrm{mL}$ TSP-1 significantly enhanced
DCFDA fluorescence, reflecting ROS production, but did not significantly enhance ceramide abundance suggesting that TSP-1 affects RBC redox balance favoring their suicidal death.

Since CD47 is a receptor for TSP-1 and CD47signaling can regulate cytoplasmic $\mathrm{Ca}^{2+}$ dynamics [12], an anti-CD47 mAb could induce an increased $\mathrm{RBC}$ intracellular $\mathrm{Ca}^{2+}$ level. For this, anti-CD47 mAb 1F7 was used as it has been shown to induce apoptosis in other cell types [29, 31]. As illustrated in Fig. 3a and b, exposure of RBCs to mAb 1F7 $(10 \mu \mathrm{g} / \mathrm{mL})$ for $1-4 \mathrm{~h}$ significantly increased Fluo3 fluorescence. However, such an effect of mAb $1 F 7$ was absent after a 24-h incubation (Fig. 3b). We observed that mAb 1F7 $(0.1-10 \mu \mathrm{g} / \mathrm{mL})$ dose-dependently increased the percentage of annexin $\mathrm{V}$ positive RBCs after a 24-h incubation (Fig. 3c). In addition, there was a time-dependent increase in the percentage of annexin $\mathrm{V}$-positive RBCs in response to mAb 1F7 (Fig. 3d). Interestingly, similar levels of RBC PS exposure in response to $\mathrm{mAb} 1 \mathrm{~F} 7$ were also seen in the absence of extracellular $\mathrm{Ca}^{2+}$ during incubation (Fig. 3e).

\section{Effect of thrombospondin-1 on morphology and deformability of human red blood cells}

The effect of TSP-1 on RBC morphology and deformability was determined. In imaging flow cytometry analyses, it was observed that the proportion of RBCs with

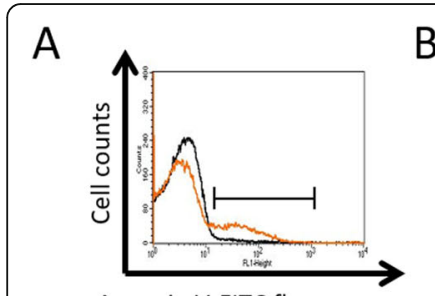

Annexin V-FITC fluorescence
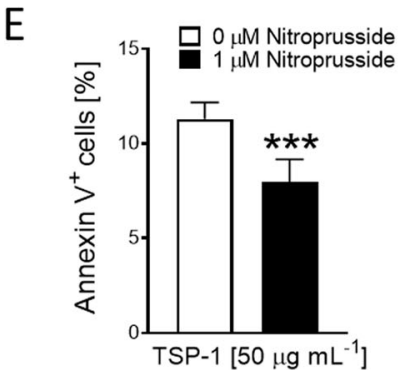

C

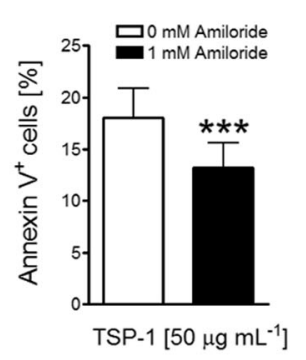

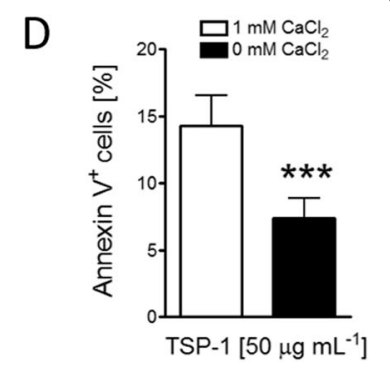

G
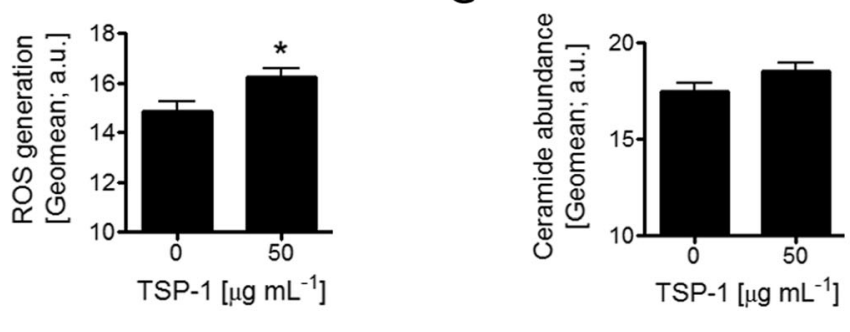

Fig. 2 Effect of thrombospondin-1 on phosphatidylserine externalization, sphingomyelinase activation, and the generation of reactive oxygen species in human red blood cells. Representative histogram (Black line: $0 \mu \mathrm{g} / \mathrm{mL}$ TSP-1, orange line: $50 \mu \mathrm{g} / \mathrm{mL}$ TSP-1; $\mathbf{a}$ and means \pm SEM. $\mathbf{b}$ of annexin $V$ positive RBCs $(n=7)$ following 48 -h incubation at $37^{\circ} \mathrm{C}$ in Ringer's solution containing $0-50 \mu \mathrm{g} / \mathrm{mL} \mathrm{TSP}-1 .{ }^{* * *}$ indicate significant difference $(P<0.001)$ from the absence of TSP-1. Means \pm SEM of annexin $V$ positive RBCs following $48-h$ incubation in $50 \mu g / m L$ TSP-1 in the absence or presence of $1 \mathrm{mM}$ amiloride $(n=27 ; \mathbf{c}), 1 \mathrm{mM} \mathrm{CaCl}_{2}(n=8 ; \mathbf{d})$ or $1 \mu \mathrm{M}$ sodium nitroprusside $(n=12 ; \mathbf{e})$. ${ }^{* * *}$ indicates significant difference $(P<0.001)$ from the absence of amiloride, $\mathrm{CaCl}_{2}$ or sodium nitroprusside. Means \pm SEM of the geometric means of DCFDA ( $n=9$; $\mathbf{f}$ ) or ceramide-dependent $(n=14 ; \mathbf{g})$ fluorescence of RBCs following 48-h incubation without or with $50 \mu \mathrm{g} / \mathrm{mL}$ TSP-1. * indicates significant difference $(P<0.05)$ from the absence of TSP-1 
A

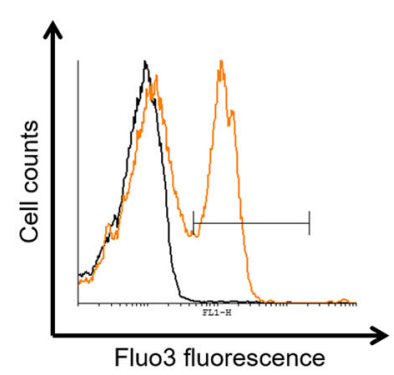

C

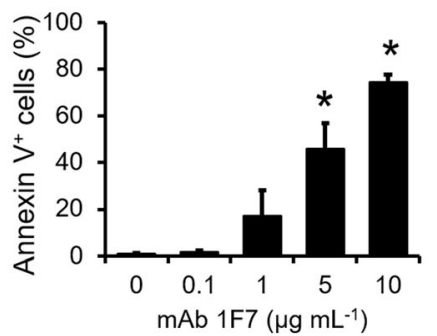

B

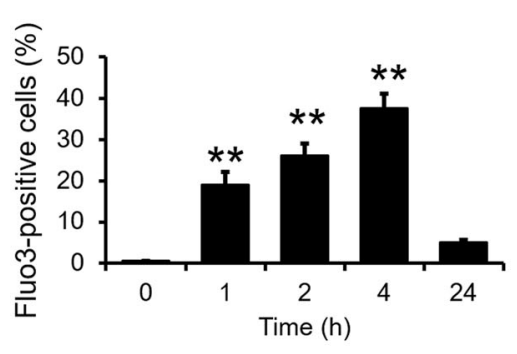

D

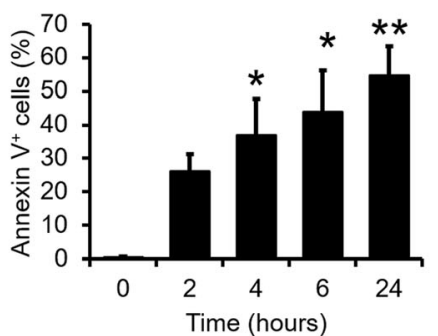

E $\quad \mathbf{1} \mathrm{mM} \mathrm{CaCl} 2$

$0 \mathrm{mM} \mathrm{CaC} 2$

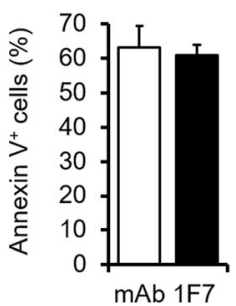

Fig. 3 Effects of the anti-CD47 mAb 1F7 on cytosolic Ca ${ }^{2+}$ levels and phosphatidylserine exposure in human red blood cells. Representative histogram (Black line: $0 \mu \mathrm{g} / \mathrm{mL} \mathrm{mAb} 1 \mathrm{F7}$, orange line: $10 \mu \mathrm{g} / \mathrm{mL} \mathrm{mAb} 1 \mathrm{~F} 7$, following a 4-h incubation; a) and means \pm SEM. b of Fluo3-positive $\operatorname{RBCs}(\%)(n=6 ; \mathbf{b})$ following incubation for $0-24 \mathrm{~h}$ at $37^{\circ} \mathrm{C}$ in the presence of $10 \mu \mathrm{g} / \mathrm{mL} \mathrm{mAb} 1 \mathrm{~F} 7 .{ }^{* *}$ indicate significant difference $(P<0.01)$ from the zero time-point. c Means \pm SEM of annexin $V$ positive RBCs $(n=3)$ following $24-h$ incubation with $0-10 \mu \mathrm{g} / \mathrm{mL} \mathrm{mAb} 1 \mathrm{~F} 7 .{ }^{*}$ indicates significant difference $(P<0.05)$ from the absence of mAb 1F7. d Means \pm SEM of annexin $V$ positive RBCs $(n=5)$ following incubation with $10 \mu \mathrm{g} /$ $\mathrm{mL} \mathrm{mAb} 1 \mathrm{~F} 7$ for $0-24 \mathrm{~h} .{ }^{*}$ and ${ }^{* *}$ indicate significant difference $(P<0.05$ and $P<0.01$, respectively) from the zero time-point. e Means \pm SEM of annexin $\mathrm{V}$ positive RBCs $(n=7)$ following $24-\mathrm{h}$ incubation with $10 \mu \mathrm{g} / \mathrm{mL} \mathrm{mAb} 1 \mathrm{~F} 7$ in the absence or presence of $1 \mathrm{mM}$ CaCl 2

smooth disc shape was significantly reduced and RBCs with crenated sphere shape were significantly increased after a 48-h incubation in the presence of TSP-1 (Fig. 4a). Accordingly, as shown in Fig. 4b, TSP-1 treatment significantly reduced the morphology index of RBCs. Ektacytometry analyses revealed that TSP-1 treatment affected RBC deformability (Fig. 4c). As depicted in Fig. 4d, in comparison to untreated RBCs, TSP-1 $(50 \mu \mathrm{g} / \mathrm{mL})$ exposure for $48 \mathrm{~h}$ significantly reduced maximum elongation index $\left(\mathrm{EI}_{\max }\right)$ suggesting that TSP-1 induces increased RBC stiffness. Furthermore, TSP-1 $(50 \mu \mathrm{g} / \mathrm{mL})$ treatment tended to increase $K_{\mathrm{EI}}$ reflecting $\mathrm{RBC}$ rigidity (Fig. 4e). Thus, the ability of RBCs to adopt a new shape in response to deforming forces, which dictate their rheological properties, is affected by TSP-1.

\section{Effect of thrombospondin-1 on microvesiculation of human red blood cells}

The impact of TSP-1-induced RBC dysfunction on microvesiculation was assessed. As shown in Fig. 5b and c, incubation of RBCs with TSP-1 for $48 \mathrm{~h}$ significantly increased $\mathrm{CD} 47^{+} / \mathrm{CD} 235 \mathrm{a}^{+}$MPs relative to $\mathrm{RBC}$ count, as compared to untreated RBCs indicating that TSP-1 promotes MP shedding.

\section{Discussion}

Compelling molecular evidence points to an essential role for CD47-dependent TSP-1 signaling in the pathophysiology of a wide range of systemic diseases [3-6]. However, little is known about this signaling mechanism in influencing anucleate $\mathrm{RBC}$ functions. Increase of cytoplasmic $\mathrm{Ca}^{2+}$ levels is a vital element in potentiating premature cell death and clearance of circulating RBCs [21,37]. In the current study, we demonstrate, for the first time, that exogenous TSP-1 causes RBC dysfunction evoking an increase in intracellular $\mathrm{Ca}^{2+}$ levels, triggering cell death, and altering cell morphology and rheological properties.

Increased intracellular $\mathrm{Ca}^{2+}$ concentration in $\mathrm{RBCs}$, triggered by the opening of NSCC, stimulates phospholipid scrambling, bleb formation, and vesiculation of the cell membrane $[21,28]$. Enhanced cytosolic $\mathrm{Ca}^{2+}$ is further involved in the activation of multiple $\mathrm{Ca}^{2+}$-sensitive enzymes such as transglutaminases, phospholipases, calpains, protein kinases and phosphatases [21]. While the molecular identity of the cation channels remains incompletely characterized, it is believed to involve the TRPC6 channel [21, 28]. According to our data, the TSP-1-elicited increase in the cytosolic $\mathrm{Ca}^{2+}$ concentration could be corroborated using whole-cell patch-clamp recordings which showed the presence of a TSP-1induced inward current, alluding to a possible $\mathrm{Ca}^{2+}$ 


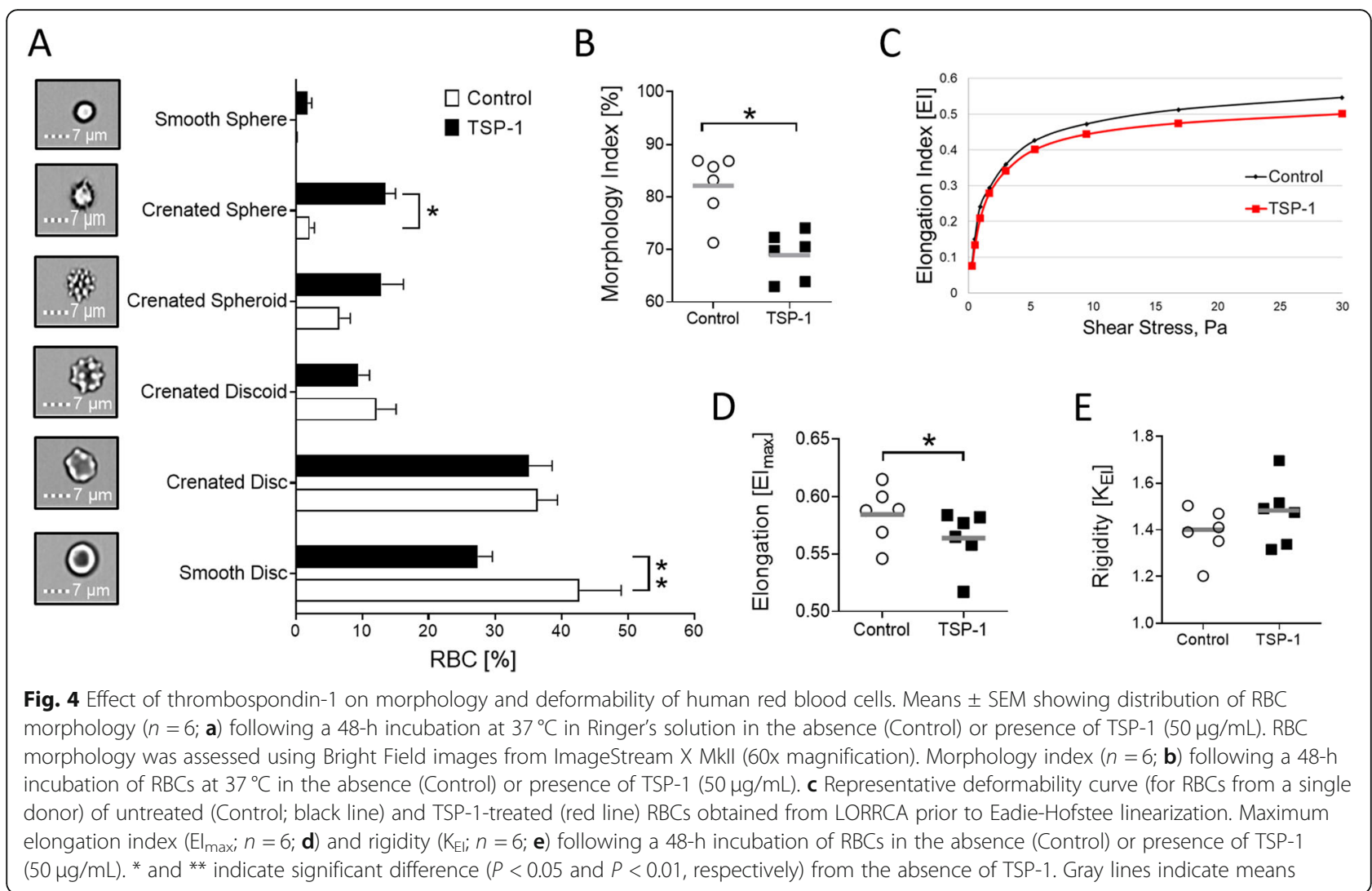

influx. In addition, we also observed that ligation of the anti-CD47 mAb 1F7 induced an increase in RBC cytosolic $\mathrm{Ca}^{2+}$ levels. These findings are consistent with previous studies in nucleated cells, which suggest that CD47/TSP-1 signal transduction impacts cellular $\mathrm{Ca}^{2+}$ homeostasis [38-40]. Notably, intact TSP-1 was previously demonstrated to upregulate intracellular $\mathrm{Ca}^{2+}$ levels in fibroblasts; this effect was recapitulated by the TSP-1derived peptide RFYVVMWK underlining the primordial role of TSP-1/CD47 signaling in regulating cytoplasmic $\mathrm{Ca}^{2+}$ levels [38]. Furthermore, cardiac myocytes treated with $7 \mathrm{~N} 3$, a peptide derived from the C-terminal of TSP1 , displayed acutely elevated intracellular $\mathrm{Ca}^{2+}$ levels through the release of $\mathrm{Ca}^{2+}$ from the sarcoplasmic reticulum [39].

Ample evidence underscores the role of oxidative stress in modulating $\mathrm{RBC} \mathrm{Ca}{ }^{2+}$ homeostasis and survival by stimulating NSCC conductance [41]. In accordance, our data reveal that TSP-1 treatment stimulated a subtle increase in RBC ROS production, which, in turn, may favor $\mathrm{Ca}^{2+}$ entry and promote cell death. TSP-1 has previously been shown to potentiate ROS generation in vascular smooth muscle cells via CD47-dependent activation of NADPH oxidase 1 [42]. TSP-1 has further been implicated in oxidative stress-mediated renal ischemia-reperfusion injury by stimulating ROS production in renal tubular endothelial cells [43]. In addition, the present study also revealed that pharmacological NO supplementation significantly blunted TSP-1-induced PS externalization in RBCs. NO was previously shown to influence RBC survival by modulating cell death pathways downstream of intracellular $\mathrm{Ca}^{2+}$ increase, but not by directly influencing $\mathrm{Ca}^{2+}$ entry per se [44]. In purview of these findings, NO has previously been documented to be an essential effector of TSP-1 signaling in a wide range of cell types, and is associated with various clinical conditions $[3,45]$.

RBC CD47 serves as a putative molecular switch in erythrophagocytosis [46]. Through activation of signaling mediated by tyrosine phosphatases, downstream of its interaction with SIRP $\alpha$, CD47 inhibits phagocytosis, and thereby functions as a "do not eat me" signal [11]. Paradoxically, however, CD47 in experimentally aged RBCs was shown to undergo a conformational change and increased binding to TSP-1, which, in turn, promoted phagocytosis [46]. It is, therefore, possible that PS externalization during RBC cell death induced by TSP$1 / C D 47$ signaling contributes, at least in part, to this "eat me" response.

RBCs exhibit an extraordinary ability to deform which facilitates their smooth passage in the microcirculation and, thus, aids in maintaining optimal rheology [47]. Increased RBC stiffness facilitates the elimination of senescent and 


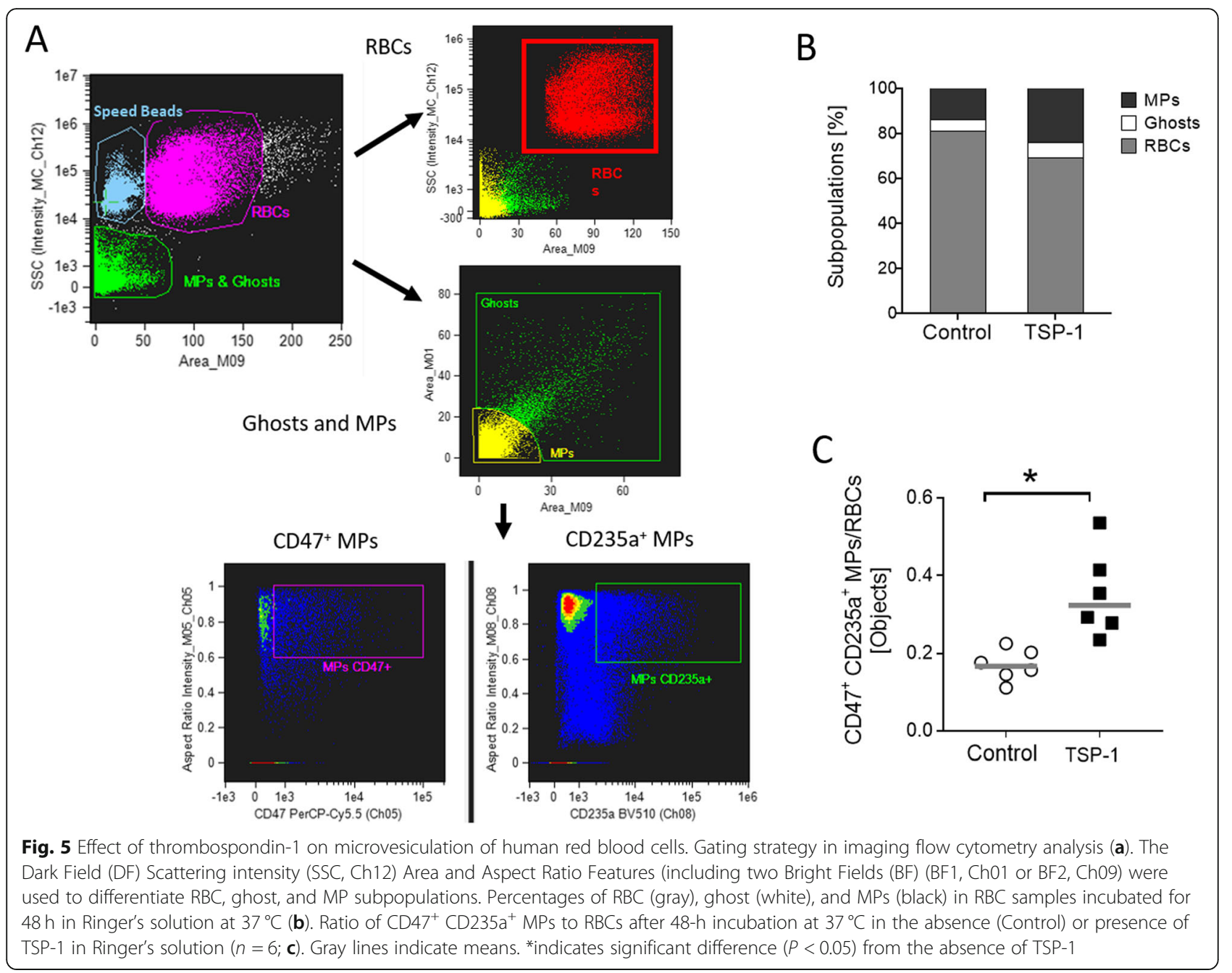

injured RBCs from the circulation in the spleen [48]. Previous studies have elucidated the pivotal role of RBC NO synthase-derived $\mathrm{NO}$ in the regulation of RBC deformability $[49,50]$. On the other hand, elevated cytoplasmic $\mathrm{Ca}^{2+}$ levels in RBCs are associated with reduced deformability [51]. Along these lines, we observed that TSP-1 treatment altered the indices of RBC deformability at exposure durations, which also elicited both enhanced cellular $\mathrm{Ca}^{2+}$ concentration and cell death. As RBC rigidity is an important hemorheological parameter leading to reduced blood viscosity, our findings may explain the occurrence of vaso-occlusive events associated with enhanced TSP-1 plasma levels [52].

TSP-1 has previously been implicated in the pathophysiology of vascular occlusion and pulmonary hypertension associated with sickle cell disease (SCD) $[53,54]$. Increased prothrombotic risk in SCD is linked to elevated TSP-1 levels, which not only inhibit ADAMTS13 proteolysis of von Willebrand Factor [55], but also provoke RBC MP shedding; this process, in turn, favors $\mathrm{RBC}$ adhesion to endothelial cells as well as stimulation of endothelial cell apoptosis [56]. Our data confirm MP shedding from RBCs following exposure to TSP-1 in vitro. Mechanistically, MP shedding by RBCs, as elucidated during their storage under blood banking conditions, may be a consequence of ATP depletion, $\mathrm{K}^{+}$ leakage, and elevation of intracellular $\mathrm{Ca}^{2+}$ [16] It may, therefore, be inferred that TSP-1-induced increase of intracellular $\mathrm{Ca}^{2+}$ concentration leads to activation of $\mathrm{Ca}^{2+}$-dependent proteases leading to cytoskeletal damage and MP shedding [16]. Intriguingly, both TSP-1 and the CD47 agonist 4 N1-1 have been shown to potentiate the transformation of cell shape in SCD from discocytes to echinocytes [56]. It is well established that an increased proportion of RBCs in SCD patients expose procoagulant PS on their surface, which may lead to thrombosis [57]. It is, therefore, reasonable to conjecture that hyperactive cation currents in RBCs are an important underlying mechanism of RBC dysfunction and thrombosis in SCD patients. TSP-1 may contribute to this channel activation.

Accelerated cell death of RBCs has been shown to occur in a variety of systemic conditions and may contribute to 
anemia, thrombosis, and impaired microcirculation in these disorders [21]. At least in theory, increased TSP-1 levels, encountered in these conditions, may aggravate $\mathrm{RBC} \mathrm{Ca}^{2+}$ entry leading to RBC cell death [21]. Remarkably, TSP-1 serum concentrations were documented to be 100 -fold higher than plasma concentrations indicating TSP-1 release by platelets [58]. TSP- 1 concentrations used in this study $(1-50 \mu \mathrm{g} / \mathrm{mL})$ are well in the range of plasma and serum levels achieved in conditions such as SCD [53], and interstitial pneumonia [59], respectively. Furthermore, $100 \mu \mathrm{g} / \mathrm{mL}$ of TSP-1 was previously used to demonstrate the impact of CD47 ligation on RBC viability in vitro [20].

\section{Conclusions}

Taken together, our data unravel that TSP-1/CD47 signaling mediates enhanced $\mathrm{RBC} \mathrm{Ca}{ }^{2+}$ concentration contributing to cell death. Targeting this signaling pathway may represent a possible therapeutic option in mitigating RBC-related pathophysiology in different clinical conditions associated with elevated TSP-1 levels.

\section{Abbreviations}

ATP: Adenosine triphosphate; DCFDA: 2',7'-dichlorodihydrofluorescein diacetate; $\mathrm{El}_{\text {max }}$ : Maximum elongation index; $\mathrm{K}_{\mathrm{El}}$ : Rigidity; LORRCA: Laserassisted optical rotational red cell analyzer; MP: Microparticles; NO: Nitric oxide; NSCC: Non-selective cation channels; PS: Phosphatidylserine; PVP: Polyvinylpyrrolidone; RBC: Red blood cell; ROS: Reactive oxygen species; SCD: Sickle cell disease; SIRPa: Signal regulatory protein a; TSP-

1: Thrombospondin 1

\section{Acknowledgements}

The authors gratefully acknowledge the technical support by $V$. Bhakta. The authors thank Prof. F. Lang for generously providing access to equipment. Imaging flow cytometry experiments were performed at the University of Alberta Faculty of Medicine \& Dentistry Flow Cytometry Facility, which receives financial support from the Faculty of Medicine \& Dentistry and Canada Foundation for Innovation awards to contributing investigators.

\section{Authors' contributions}

$R B, J P A$, and SMQ designed the study; RB, PPK, OM, EN, DAD, AAMB, TD, MG, and SMQ performed the experiments and/or analysed the data; RB, WPS, LK, $F A, P A O, J P A$, and SMQ interpreted the data of the study. RB and SMQ wrote the manuscript. The authors read and approved the final manuscript.

\section{Funding}

RB is supported by Deutsche Forschungsgemeinschaft (Project nr. 426724658). PAO was supported by grants from the Swedish Research Council (2012-2702) and the Faculty of Medicine, Umeå University. OM, DAD, WPS, JPA, and SMQ were supported by resources from Canadian Blood Services (CBS). OM is a recipient of CBS postdoctoral fellowship. As a condition of Canadian government funding, this report must contain the statement, "The views expressed herein do not necessarily represent the view of the federal government of Canada". Open access funding was provided by Projekt DEAL.

\section{Availability of data and materials}

The datasets used and/or analyzed during the current study are available from the corresponding author on reasonable request.

\section{Ethics approval and consent to participate}

Provided in Methods section.

\section{Consent for publication}

All authors read and approved the final manuscript.

\section{Competing interests}

The authors declare that they have no competing interests with the contents of this article.

\section{Author details}

${ }^{1}$ Department of Internal Medicine, Division of Endocrinology, Diabetology, and Nephrology, Universitätsklinikum Tübingen, Tübingen, Germany. ${ }^{2}$ Institute of Neurobiology, Bulgarian Academy of Sciences, Sofia, Bulgaria. ${ }^{3}$ Centre for Innovation, Canadian Blood Services, Edmonton, AB, Canada. ${ }^{4}$ Department of Laboratory Medicine and Pathology, University of Alberta, Edmonton, $\mathrm{AB}$, Canada. ${ }^{5}$ Department of Integrative Medical Biology, Umeå University, Umeå, Sweden. ${ }^{6}$ Centre for Innovation, Canadian Blood Services, Hamilton, ON, Canada. 'Department of Pathology and Molecular Medicine, McMaster University, Hamilton, ON, Canada. Institute of Molecular and Cellular Sports Medicine, German Sport University of Cologne, Köln, Germany. ${ }^{9}$ Department of Physiology, Eberhard-Karls University, Tübingen, Germany. ${ }^{10}$ Institute of Diabetes Research and Metabolic Diseases of the Helmholtz Center Munich at Eberhard-Karls University, Tübingen, Germany.

${ }^{11}$ German Center for Diabetes Research (DZD), Eberhard-Karls University,

Tübingen, Germany. ${ }^{12}$ Theoretical Medicine and Biosciences, Saarland University, Homburg, Germany. ${ }^{13}$ Experimental Physics, Saarland University, Saarbruecken, Germany. ${ }^{14}$ Faculty of Health Sciences, Ontario Tech University, Oshawa, ON, Canada.

Received: 17 July 2020 Accepted: 24 August 2020

Published online: 18 September 2020

\section{References}

1. Lopez-Dee Z, Pidcock K, Gutierrez LS. Thrombospondin-1: multiple paths to inflammation. Mediat Inflamm. 2011;2011:296069.

2. Krishna SM, Golledge J. The role of thrombospondin-1 in cardiovascular health and pathology. Int J Cardiol. 2013;168(2):692-706.

3. Rogers NM, Sharifi-Sanjani M, Csanyi G, Pagano PJ, Isenberg JS. Thrombospondin-1 and CD47 regulation of cardiac, pulmonary and vascular responses in health and disease. Matrix Biol. 2014;37:92-101.

4. Zhao C, Isenberg JS, Popel AS. Human expression patterns: qualitative and quantitative analysis of thrombospondin-1 under physiological and pathological conditions. J Cell Mol Med. 2018;22(4):2086.

5. Gonzalez-Quesada C, Cavalera M, Biernacka A, Kong P, Lee DW, Saxena A, et al. Thrombospondin-1 induction in the diabetic myocardium stabilizes the cardiac matrix in addition to promoting vascular rarefaction through angiopoietin-2 upregulation. Circ Res. 2013;113(12):1331-44.

6. Rogers NM, Yao M, Novelli EM, Thomson AW, Roberts DD, Isenberg JS. Activated CD47 regulates multiple vascular and stress responses: implications for acute kidney injury and its management. Am J Physiol Ren Physiol. 2012;303(8):F1117-25.

7. Jimenez B, Volpert OV, Crawford SE, Febbraio M, Silverstein RL, Bouck N. Signals leading to apoptosis-dependent inhibition of neovascularization by thrombospondin-1. Nat Med. 2000;6(1):41-8.

8. Mateo V, Lagneaux L, Bron D, Biron G, Armant M, Delespesse G, et al. CD47 ligation induces caspase-independent cell death in chronic lymphocytic leukemia. Nat Med. 1999:5(11):1277-84.

9. Aurora AB, Biyashev D, Mirochnik Y, Zaichuk TA, Sanchez-Martinez C, Renault MA, et al. NF-kappaB balances vascular regression and angiogenesis via chromatin remodeling and NFAT displacement. Blood. 2010;116(3):475-84.

10. Friedl P, Vischer P, Freyberg MA. The role of thrombospondin-1 in apoptosis. Cell Mol Life Sci. 2002;59(8):1347-57.

11. Oldenborg PA. CD47: a cell surface glycoprotein which regulates multiple functions of hematopoietic cells in health and disease. ISRN Hematol. 2013;2013:614619.

12. Soto-Pantoja DR, Kaur S, Roberts DD. CD47 signaling pathways controlling cellular differentiation and responses to stress. Crit Rev Biochem Mol Biol. 2015;50(3):212-30

13. Oldenborg PA, Gresham HD, Lindberg FP. CD47-signal regulatory protein alpha (SIRPalpha) regulates Fcgamma and complement receptor-mediated phagocytosis. J Exp Med. 2001;193(7):855-62.

14. Oldenborg PA, Zheleznyak A, Fang YF, Lagenaur CF, Gresham HD, Lindberg FP. Role of CD47 as a marker of self on red blood cells. Science. 2000; 288(5473):2051-4

15. Antonelou MH, Kriebardis AG, Papassideri IS. Aging and death signalling in mature red cells: from basic science to transfusion practice. Blood Transfus. 2010;8(Suppl 3):s39-47. 
16. Said AS, Doctor A. Influence of red blood cell-derived microparticles upon vasoregulation. Blood Transfus. 2017;15(6):522-34.

17. De Oliveira S, Vitorino de Almeida V, Calado A, Rosario HS, Saldanha C. Integrin-associated protein (CD47) is a putative mediator for soluble fibrinogen interaction with human red blood cells membrane. Biochim Biophys Acta. 2012;1818(3):481-90.

18. Wiewiora M, Piecuch J, Sedek L, Mazur B, Sosada K. The effects of obesity on CD47 expression in erythrocytes. Cytometry B Clin Cytom. 2017;92(6):485-91.

19. Grobler C, Maphumulo SC, Grobbelaar LM, Bredenkamp JC, Laubscher GJ, Lourens PJ, et al. Covid-19: the rollercoaster of fibrin(Ogen), D-dimer, Von Willebrand factor, P-Selectin and their interactions with endothelial cells, platelets and erythrocytes. Int J Mol Sci. 2020;21:14.

20. Head DJ, Lee ZE, Swallah MM, Avent ND. Ligation of CD47 mediates phosphatidylserine expression on erythrocytes and a concomitant loss of viability in vitro. Br J Haematol. 2005;130(5):788-90.

21. Qadri SM, Bissinger R, Solh Z, Oldenborg PA. Eryptosis in health and disease: a paradigm shift towards understanding the (patho)physiological implications of programmed cell death of erythrocytes. Blood Rev. 2017;31(6):349-61.

22. Georgatzakou HT, Antonelou MH, Papageorgiou EG, Kriebardis AG. "Valar morghulis": all red cells must die. Blood Transfus. 2020;18(2):83-5.

23. Pretorius E, du Plooy JN, Bester J. A comprehensive review on Eryptosis. Cell Physiol Biochem. 2016;39(5):1977-2000.

24. Kaestner L, Bogdanova A, Egee S. Calcium channels and calcium-regulated channels in human red blood cells. Adv Exp Med Biol. 2020;1131:625-48

25. Huber SM, Duranton C, Lang F. Patch-clamp analysis of the "new permeability pathways" in malaria-infected erythrocytes. Int Rev Cytol. 2005; 246:59-134.

26. Lang KS, Duranton C, Poehlmann H, Myssina S, Bauer C, Lang F, et al. Cation channels trigger apoptotic death of erythrocytes. Cell Death Differ. 2003; 10(2):249-56.

27. Nemkov T, Qadri SM, Sheffield WP, D'Alessandro A. Decoding the metabolic landscape of pathophysiological stress-induced cell death in anucleate red blood cells. Blood Transfus. 2020;18(2):130-42.

28. Lang E, Qadri SM, Lang F. Killing me softly - suicidal erythrocyte death. Int J Biochem Cell Biol. 2012;44(8):1236-43.

29. Manna PP, Frazier WA. CD47 mediates killing of breast tumor cells via Gidependent inhibition of protein kinase a. Cancer Res. 2004;64(3):1026-36.

30. Brown E, Hooper L, Ho T, Gresham H. Integrin-associated protein: a 50-kD plasma membrane antigen physically and functionally associated with integrins. J Cell Biol. 1990;111(6 Pt 1):2785-94.

31. Manna PP, Frazier WA. The mechanism of CD47-dependent killing of T cells: heterotrimeric Gi-dependent inhibition of protein kinase a. J Immunol. 2003; 170(7):3544-53.

32. Qadri SM, Chen D, Schubert P, Perruzza DL, Bhakta V, Devine DV, et al. Pathogen inactivation by riboflavin and ultraviolet light illumination accelerates the red blood cell storage lesion and promotes eryptosis. Transfusion. 2017;57(3):661-73.

33. Erdbrugger U, Rudy CK, Etter ME, Dryden KA, Yeager M, Klibanov AL, et al. Imaging flow cytometry elucidates limitations of microparticle analysis by conventional flow cytometry. Cytometry A. 2014;85(9):756-70.

34. Headland SE, Jones HR, D'Sa AS, Perretti M, Norling LV. Cutting-edge analysis of extracellular microparticles using image stream $(X)$ imaging flow cytometry. Sci Rep. 2014;4:5237.

35. Pinto RN, Sebastian JA, Parsons MJ, Chang TC, Turner TR, Acker JP, et al. Label-free analysis of red blood cell storage lesions using imaging flow Cytometry. Cytometry A. 2019;95(9):976-84.

36. Stadnick H, Onell R, Acker JP, Holovati JL. Eadie-Hofstee analysis of red blood cell deformability. Clin Hemorheol Microcirc. 2011;47(3):229-39.

37. Larsson A, Hult A, Nilsson A, Olsson M, Oldenborg PA. Red blood cells with elevated cytoplasmic $\mathrm{Ca}(2+)$ are primarily taken up by splenic marginal zone macrophages and CD207+ dendritic cells. Transfusion. 2016;56(7):1834-44.

38. Tsao PW, Mousa SA. Thrombospondin mediates calcium mobilization in fibroblasts via its Arg-Gly-asp and carboxyl-terminal domains. J Biol Chem. 1995:270(40):23747-53

39. Sharifi-Sanjani M, Shoushtari AH, Quiroz M, Baust J, Sestito SF, Mosher M, et al. Cardiac CD47 drives left ventricular heart failure through Ca2+-CaMKIlregulated induction of HDAC3. J Am Heart Assoc. 2014;3(3):e000670.

40. Bauer EM, Qin Y, Miller TW, Bandle RW, Csanyi G, Pagano PJ, et al. Thrombospondin-1 supports blood pressure by limiting eNOS activation and endothelial-dependent vasorelaxation. Cardiovasc Res. 2010;88(3):471-81.
41. Bissinger R, Bhuyan AAM, Qadri SM, Lang F. Oxidative stress, eryptosis and anemia: a pivotal mechanistic nexus in systemic diseases. FEBS J. 2019; 286(5):826-54.

42. Csanyi G, Yao M, Rodriguez Al, Al Ghouleh I, Sharifi-Sanjani M, Frazziano G, et al. Thrombospondin-1 regulates blood flow via CD47 receptor-mediated activation of NADPH oxidase 1. Arterioscler Thromb Vasc Biol. 2012;32(12): 2966-73.

43. Yao M, Rogers NM, Csanyi G, Rodriguez Al, Ross MA, St Croix C, et al. Thrombospondin-1 activation of signal-regulatory protein-alpha stimulates reactive oxygen species production and promotes renal ischemia reperfusion injury. J Am Soc Nephrol. 2014:25(6):1171-86.

44. Nicolay JP, Liebig G, Niemoeller OM, Koka S, Ghashghaeinia M, Wieder T, et al. Inhibition of suicidal erythrocyte death by nitric oxide. Pflugers Arch. 2008;456(2):293-305

45. Rogers NM, Ghimire K, Calzada MJ, Isenberg JS. Matricellular protein thrombospondin-1 in pulmonary hypertension: multiple pathways to disease. Cardiovasc Res. 2017;113(8):858-68.

46. Burger $P$, Hilarius-Stokman $P$, de Korte $D$, van den Berg TK, van Bruggen $R$. CD47 functions as a molecular switch for erythrocyte phagocytosis. Blood. 2012;119(23):5512-21.

47. Pretorius E. Erythrocyte deformability and eryptosis during inflammation, and impaired blood rheology. Clin Hemorheol Microcirc. 2018:69(4):545-50.

48. Safeukui I, Buffet PA, Deplaine G, Perrot S, Brousse V, Sauvanet A, et al. Sensing of red blood cells with decreased membrane deformability by the human spleen. Blood Adv. 2018;2(20):2581-7.

49. Grau M, Pauly S, Ali J, Walpurgis K, Thevis M, Bloch W, et al. RBC-NOSdependent S-nitrosylation of cytoskeletal proteins improves RBC deformability. PLoS One. 2013;8(2):e56759.

50. Grau M, Jerke M, Nader E, Schenk A, Renoux C, Collins B, et al. Effect of acute exercise on RBC deformability and RBC nitric oxide synthase signalling pathway in young sickle cell anaemia patients. Sci Rep. 2019;9(1):11813.

51. Barodka V, Mohanty JG, Mustafa AK, Santhanam L, Nyhan A, Bhunia AK, et al. Nitroprusside inhibits calcium-induced impairment of red blood cell deformability. Transfusion. 2014;54(2):434-44.

52. Novelli EM, Kato GJ, Ragni MV, Zhang Y, Hildesheim ME, Nouraie M, et al. Plasma thrombospondin-1 is increased during acute sickle cell vasoocclusive events and associated with acute chest syndrome, hydroxyurea therapy, and lower hemolytic rates. Am J Hematol. 2012;87(3):326-30.

53. Faulcon LM, Fu Z, Dulloor P, Barron-Casella E, Savage W, Jennings JM, et al. Thrombospondin-1 and L-selectin are associated with silent cerebral infarct in children with sickle cell anaemia. Br J Haematol. 2013;162(3):421-4.

54. Novelli EM, Little-Ihrig L, Knupp HE, Rogers NM, Yao M, Baust JJ, et al. Vascular TSP1-CD47 signaling promotes sickle cell-associated arterial vasculopathy and pulmonary hypertension in mice. Am J Phys Lung Cell Mol Phys. 2019;316(6):L1150-64.

55. Novelli EM, Kato GJ, Hildesheim ME, Barge S, Meyer MP, Lozier J, et al. Thrombospondin-1 inhibits ADAMTS13 activity in sickle cell disease. Haematologica. 2013:98(11):e132-4

56. Camus SM, Gausseres B, Bonnin P, Loufrani L, Grimaud L, Charue D, et al. Erythrocyte microparticles can induce kidney vaso-occlusions in a murine model of sickle cell disease. Blood. 2012;120(25):5050-8.

57. Weiss E, Cytlak UM, Rees DC, Osei A, Gibson JS. Deoxygenation-induced and $\mathrm{Ca}(2+)$ dependent phosphatidylserine externalisation in red blood cells from normal individuals and sickle cell patients. Cell Calcium. 2012;51(1):51-6.

58. Barclay JL, Keshvari S, Whitehead JP, Inder WJ. Development of an enzyme-linked immunosorbent assay for thrombospondin-1 and comparison of human plasma and serum concentrations. Ann Clin Biochem. 2016:53(Pt 5):606-10.

59. Ide M, Ishii H, Mukae H, Iwata A, Sakamoto N, Kadota J, et al. High serum levels of thrombospondin-1 in patients with idiopathic interstitial pneumonia. Respir Med. 2008;102(11):1625-30.

\section{Publisher's Note}

Springer Nature remains neutral with regard to jurisdictional claims in published maps and institutional affiliations. 